BULLETIN Bulletin hispanique

HISPANIQUE Université Michel de Montaigne Bordeaux

121-1 | 2019

La épica en el mundo hispánico (Siglo de Oro)

Baltasar de Céspedes, Discurso de las letras humanas llamado "El Humanista" edición, estudio y notas de Mercedes COMELLAS. Prólogo de Francisco RICO

Real Academia Española, Madrid, 2018

Juan Francisco Alcina Rovira

(2) OpenEdition

Journals

Edición electrónica

URL: https://journals.openedition.org/bulletinhispanique/8211

DOI: 10.4000/bulletinhispanique.8211

ISSN: 1775-3821

Editor

Presses universitaires de Bordeaux

Edición impresa

Fecha de publicación: 24 junio 2019

Paginación: 374-381

ISBN: 979-10-300-0363-5

ISSN: 0007-4640

Referencia electrónica

Juan Francisco Alcina Rovira, «Baltasar de Céspedes, Discurso de las letras humanas Ilamado "El Humanista" edición, estudio y notas de Mercedes comellas. Prólogo de Francisco Rico», Bulletin hispanique [En línea], 121-1 | 2019, Publicado el 24 junio 2019, consultado el 02 enero 2023. URL: http://journals.openedition.org/bulletinhispanique/8211 ; DOl: https://doi.org/10.4000/ bulletinhispanique.8211

Este documento fue generado automáticamente el 2 enero 2023.

All rights reserved 


\section{Baltasar de Céspedes, Discurso de las letras humanas llamado "El Humanista" edición, estudio y notas de Mercedes comellas. Prólogo de Francisco RICO}

Real Academia Española, Madrid, 2018

Juan Francisco Alcina Rovira

\section{REFERENCIA}

Baltasar de Céspedes, Discurso de las letras humanas llamado "El Humanista", edición, estudio y notas de Mercedes comelLAs. Prólogo de Francisco Rico, Madrid, Real Academia Española-Centro para la edición de los Clásicos Españoles, 2018 [Anejos de la Biblioteca Clásica de la Real Academia Española], ISBN 978-84-09-01000-4, 193*+ 197 págs.

1 El Discurso de las Letras es muy breve (75 páginas, de las cuales un $30 \%$ son notas) pero en ese breve espacio Céspedes es capaz de dibujar un proyecto de estudios para sus alumnos de letras bien pensado y exigente. Está dividido en dos partes de siete capítulos cada una, la primera sobre lengua (De la inteligencia del lenguaje; de la razón del lenguaje; de la ortografía; de la prosodia; de la etimología; de la sintaxis; del uso del lenguaje) y la segunda sobre disciplinas auxiliares y actividades propias del humanista (De la parte de las letras humanas que toca a las cosas; de la historia; de las fábulas; de la contemplación de las cosas; de la acción de las cosas; de los comentarios; de la traducción), además de un preámbulo y un epílogo.

2 Gregorio de Andrés (Real Monasterio de El Escorial: Biblioteca «La Ciudad de Dios» I Libros, 1965), publicó la primera edición crítica con aparato de variantes, reflejando la ortografía del siglo XVI de Céspedes (sobre 6 mss. y la edición de 1784) y la acompañó 
de un importante trabajo de documentación de archivo que sustenta la amplia biografía que precede. Pero era hora de volver sobre este texto y cubrir las ausencias de la edición de Andrés. Mercedes Comellas cumple con creces esta necesidad en tres líneas:

A. Una investigación exhaustiva sobre el entorno humanístico presentada en la amplia «Introducción» $\left(27^{*}-160^{*}\right)$, que entendemos como una continuación de su libro de 1995 El Humanista (En torno al "Discurso de las letras humanas» de Baltasar de Céspedes), Universidad de Sevilla, 1995) y de varios artículos, y que incide sobre la etapa otoñal de 1600 apoyada en todo lo que sabemos ahora sobre el humanismo hispano. No es ajeno a todo ello sino todo lo contrario Francisco Rico, autor del prólogo, quien como petrarquista (Vida u obra de Petrarca [1974]) y gran conocedor del humanismo italiano abrió el primero la puerta a los estudios sobre humanismo en España con una visión más europea, más contrastada con los originales italianos y el imprescindible conocimiento del entorno cultural hispano en el que se inscribe (la posterior investigación sobre Historia de la Filología Clásica y después los Estudios Neolatinos los han complementado). Por ello es especialmente valioso este «Prólogo» en cuanto reflexión, después de muchos años, sobre lo que es el Humanismo, especialmente el español y sus limitaciones.

B. Logro de la autora ha sido también una búsqueda importante de manuscritos del Discurso que ha permitido a M. Comellas añadir cinco manuscritos más, desconocidos anteriormente. Estos descubrimientos bibliográficos nos brindan en el capítulo 5 («Historia del texto» $160^{*}-178^{*}$ ) una perspectiva más precisa del entorno escolar que copió y transmitió el texto, en el insondable mundo de la lectura y copia de manuscritos en el Siglo de Oro.

5 C. Finalmente la autora ha podido elaborar una excelente edición crítica basada en BNE ms. 18735/50, normalizando la ortografía castellana, con abundantes notas explicativas e identificaciones de los autores que menciona Céspedes. Cuestiones ecdóticas se tratan en la sección «Esta edición» 185*-193*. La edición viene enriquecida por una copiosa anotación al pie de cada página que la hacen especialmente útil y permiten valorar con más exactitud el significado de lo que propone Céspedes.

6 El tomo consta, además del importante prólogo de F. Rico, de dos partes principales: Introducción y edición del Discurso con su aparato crítico y bibliografía. La extensa «Introducción» de Comellas se divide en cinco bloques: [1.] Baltasar de Céspedes (27*-36* Biografía y obras del autor). [2.] El Discurso de las letras humanas (37*- 44*). [3.] Humanismo en $1600\left(45^{*}-92^{*}\right)$. [4.] El plan de estudios (92*-160*). [5.] Historia del Texto $\left(160^{*}-193^{*}\right)$.

7 [1.] «Biografía». Poco se conoce sobre la vida de Céspedes antes de la etapa de profesor de retórica en Salamanca en 1583 (con varios períodos en blanco). Sólo sabemos indirectamente que nació en Granada y que obtuvo el título de Maestro en Valencia (donde quizá pudo ser alumno de Pedro Juan Núñez ${ }^{1}$, al que cita como "perfectísimo humanista y gran censor de todo género de poesía» [60] y por un libro suyo en 55). Como P. J. Núñez llevó una vida itinerante buscando sueldos y condiciones mejores hasta 1596 (cátedra de Prima de Gramática) cuando definitivamente se instala en Salamanca hasta su muerte en 1615. Allí fue colega de Sánchez de las Brozas con cuya hija se había casado en 1587 y sin duda Sanctius y Pierre de la Ramée fueron una de las influencias en sus concepciones de la ordenación de las ciencias. Pero aquí querría resaltar otra influencia, la de Antonio Agustín, arzobispo de Tarragona de 1577-1586 y señalar algunas ideas de Céspedes que se remontan a sus contactos con el aragonés. La 
noticia que tenemos sobre la presencia de Céspedes en Tarragona se limita a una estrofa del poema «La Fuente de Alcover» que empezó Agustín en $1577^{2}$ y acabó Felipe $\mathrm{Mey}^{3}$. En ella aparece en la ribera del riachuelo un cuadro de hombres notables de la familia y clan Agustín, nobles relacionados junto con sus esposas (siempre con noticias exactas como por ejemplo el noble Lluís d'Icart, que muere en abril de 1579 lo que nos da una fecha aproximada ante quem $)^{4} \mathrm{y}$ patricios locales que participan en la excursión a la que se añaden al final el sabio secretario Martín López de Bailo y a continuación una estrofa dedicada a Céspedes (p. 37): A Baltasar de Céspedes te quiero / Dar por remate desta compañía; / No digo qué hay en él, porque no espero / Que a rematar jamás acertaría; / Pues para hazerlo, es menester primero / Ir a Helicone, y ha de ser el guía: / Síguele si te lleva allá el deseo, / Qu'él te será las nueve, y su Timbreo.

8 Una primera hipótesis mía fue pensar que aparecía en «La Fuente» porque se habría contratado a Céspedes como docente en la Universidad de Tarragona de la que cuidó Agustín. Podría estar encargado de alguna de las tres Aulas de Gramática, o sea tres niveles de latín obligatorios para obtener los grados en Filosofía y Teología (los únicos que ofertaba la Universidad que había recibido nuevos estatutos con la llegada de Agustín en 1577 y en la que figuraba Joan Terés como rector). Pero pienso ahora que quizá tendría (al mismo tiempo o en exclusiva) otras obligaciones en el palacio arzobispal que incluirían trabajos de secretario (copista, traductor de griego al latín, revisor de galeradas etc.) colaborando con Bailo y quizá por ese motivo figuran los dos en estancias seguidas en el poema. Agustín siempre necesitaba colaboradores con conocimientos de griego para las infinitas obras que tenía entre manos y sería extraño que no aprovechara a un hombre como Céspedes. Lo pudo recomendar Jerónimo Zurita, amigo íntimo de Agustín y corresponsal constante hasta su muerte en 1580 (él fue quien lo había recomendado anteriormente a Hurtado de Mendoza [Andrés, 16]). Comellas data la estancia tarraconense en el hueco biográfico de 1584-86. Pero me inclino a colocarlo antes, después de 1577 y antes de 1579. Si la escena y la estancia de Céspedes se colocase en 1584 uno esperaría encontrar más bien en la nómina de «La Fuente» a André Schott que colabora con Agustín desde ese año y no mencionaría al Batlle general Lluís d'Icart que ya había fallecido. De cualquier manera esta relación entre el canonista y Céspedes concuerda y se refuerza con la lectura más atenta que podemos hacer del Discurso donde creo que es evidente la influencia de ideas de Agustín. Encaja en el hueco biográfico y justifica una larga serie de referencias a la obra del arzobispo y sus intereses (le cita 4 veces, el doble que al Brocense, aunque sea una valoración a peso) y su admiración por él llega a detalles realmente sorprendentes. Por ejemplo, quizá yo estaría de acuerdo con Céspedes cuando cita al final de una lista de grandes poetas latinos hispanos a Antonio Agustín (59), pero hay que recordar que en vida no publicó ninguno y no tuvo mucha fama ni circularon sus poemas que no llegó a recopilar dejándolos dispersos en cuadernos de notas. Evidentemente hay que atribuirlo a sus contactos con el anticuario y humanista, que le permitiría, directamente o a través de amigos, leer alguno de los raros manuscritos que los transmiten ${ }^{5}$.

[2.] El propósito del Discurso presenta algunos problemas de ese texto entre otros «principalmente por estar escrito en un momento de profunda transformación de las letras humanas y en una fecha (1600) que para muchos supera las fronteras cronológicas del humanismo». $\left(45^{*}\right)$. Comellas lo relaciona con el concepto de paideia en el sentido de un proyecto de la perfecta educación en la humanitas enlazando con los studia humanitatis renacentistas. Partiría de A. Gelio (XIII. 17,1) y el De disciplinis de L. 
Vives para cubrir las necesidades de excelencia del rito de passage de unos grupos socialmente altos del Barroco.

[3.] La sección «Humanismo en 1600» amplía y precisa el punto anterior. Va dividido en cinco apartados en un intento de comprensión de este humanismo otoñal: [A.] La erudición. [B.] La vulgarización. [C.] Nuevas escuelas de gramática y divulgación de los estudios. [D.] El término "Humanista". [E.] El humanista de Céspedes y el filólogo. En ellos se trata de la exigencia de mayores conocimientos a la antigua formación del humanista como orator et poeta y los límites que ya ponía Vives en el De disciplinis. A ello se añade la crítica de Céspedes a la vulgarización del humanismo en autores de gran fama como A. de Guevara o de Martín del Río S. J. en sus Sintagmata in Senecam que considera un «manual de predicadores» y que ofrece una erudición falsa. En suma Céspedes intenta sobre todo separarse de los gramáticos que crean infinidad de nuevas escuelas de latinidad por toda España y por otra resaltar la calidad del producto que ofrece con unas características de nivel y esfuerzo distinto del que se vendía como 'humanismo' en aquel momento. Son interesantes las partes dedicadas al término 'humanista' y sus relaciones con 'filólogo'. En realidad 'humanista' es un término en desuso en tiempos de Céspedes y se prefieren otros sinónimos como 'culto' o 'erudito'. Céspedes utiliza conscientemente ese término enlazando con la tradición de los studia humanitatis y, según Comellas, procura también marcar sus diferencias respecto a la gramática lógica de Ramus y el Brocense visible en el capítulo «Sintaxis» criticando que «la hacen teórica y especulación, con reglas intrincadas y dificultosas, no advirtiendo que en esta parte no hay otra regla que sea cierta sino es la observación de cómo hablaron los antiguos» $\left(88^{*}-89^{*}\right)$. Pero al término humanista de Céspedes se le han cortado las uñas y el aliento revolucionario del Renacimiento, y taxativamente prohíbe que el posible humanista se meta en camisa de once varas corrigiendo la filología de los Padres de la Iglesia y las Sagradas Escrituras $\left(91^{*}\right)$ y la de otras disciplinas. De todas formas a mí me parece que en el caso de temas teológicos, más que una concepción reduccionista del territorio del humanista, se trata de un consejo salvífico para no tener tratos con aquellos que "si no queman no comen", aunque también implique una reducción forzada.

11 [4.] «El plan de estudios» analiza la estructura y contenidos principales del Discurso y va dividido en: [a.] El orden y las herramientas; [b.] La lengua y las cosas; [c.] Las artes del lenguaje; [d.] Las cosas: Historia y fábula; [e.] Las disciplinas "de la contemplación"; [f.] La acción del humanista; [g.] Autoridades, referencias y citas.

Sobre [a.] El orden, podemos resaltar que Céspedes, aunque no es un ramista, sí ha asimilado muchas cosas del método del Vermandois que exige distinguir las diferentes partes del saber que deben delimitarse con precisión y no admitir encabalgamientos, así como su afán de ordenar y jerarquizar el conocimiento y su didactismo. No es una cosa rara en un yerno de un ramista como era el Brocense, aunque ni uno ni otro podían citar al beligerante calvinista, muerto en su escondite durante la SaintBarthélemy, dicen que delatado por algún compañero de claustro. No ha escapado esta influencia a Mercedes Comellas $\left(105^{*}-107^{*}\right)$ que sintetiza bien la presencia del método dialéctico de Ramus en el Discurso: «[Céspedes] no le dedica ningún apartado particular, pero su presencia marca toda la obra, articulando su disposición y su sentido.» (105*). Naturalmente los capítulos sobre la lengua son los más importantes para Céspedes [b.c., los verba, para tratar después de las cosas, de rebus (los antepasados de los Realia de 
filología clásica)] y defiende el modelo italiano de enseñanza de lengua a través del usus postergando la lectura de los gramáticos.

Sobre [d] Historia, Céspedes después de defender la veracidad histórica y dar un varapalo a fray Juan Annio recuerda en primer lugar a Agustín y las materias instrumentales que reinventó como soportes fiables de la historia y prosopografía: epigrafía y numismática ${ }^{6}\left(134^{*}\right.$ y 43-45): «Hay un libro de medallas de A. Agustín,... que fue el que más supo de esto, como de todo lo demás en nuestro tiempo.» (43). Sobre [g.] Autoridades y citas, se puede decir que probablemente procede de Agustín la crítica a la Orthographia (Venetiis: 1561) de Aldo Manuzio el Joven, de la que dice: «donde hay muchas cosas falsas y mal entendidas» (45). Se podría poner en relación con unas expresiones similares de una carta del aragonés a Orsini de 1562 dando noticia del entonces reciente «libretto di Orthographia dil figluolo di messer Paolo, anzi del padre come credo; mette alcune inscrissione false» ${ }^{7}$ que se refleja en la crítica de Céspedes. Céspedes no menciona a Ambrosio de Morales (157* n. 447) aunque Agustín, que tampoco escatima críticas a sus inscripciones, sí lo cita en la bibliografía epigráfica de los Dialogos ${ }^{8}$. Sobre Onofrio Panvinio (156* y 45-46) es justo remitir al ingente trabajo de J. L. Ferrary ${ }^{9}$. Sobre Ottavio Pantagato y su sorprendente vida y cultura, que sirvió de guía y enlace para diversos humanistas romanos hacia 1551, pienso que la más o menos precisa información de Céspedes procede directa o indirectamente de Agustín que era miembro destacado de ese grupo (46) o de algún amigo cercano ${ }^{10}$. Sobre las fábulas o mitos antiguos estaría de nuevo de acuerdo con Céspedes en que el mejor manual era el de Lilio Gregorio Giraldi, aunque en los otros, las imágenes, la poesía o la fuerza del relato puedan ser también un aliciente. Sobre la interpretación del mito, Céspedes es aristotélico y evemerístico como muchos otros, por ejemplo otra vez Agustín (cf. Diálogos de medallas 188 sobre el toro de Pasiphae).

En [5.] «La Historia del texto» se describen los diversos manuscritos con interesantes detalles sobre algunos de los escolares que los poseyeron (algunos incluyen Tabulae de raigambre ramista). Se analizan sus filiaciones y la autora ofrece su stemma; el aparato crítico, como es habitual en la colección, aparece al final, 77-111. Para cada uno de los capítulos, la editora (siguiendo las titulaciones de Céspedes) ha creado una numeración seguida de cada párrafo al que remite el aparato crítico. De hecho sirven también para precisar citas en la «Introducción» y facilitan en general las referencias al texto.

En resumen la existencia de esta guía a los estudios de humanidades anima y da cierta confianza a los que nos interesamos por el discutido humanismo español aunque sea de época tan tardía. Confirma la idea de que la brillantez de la cultura en español del Siglo de Oro podía ir acompañada de algunos buenos docentes de lenguas clásicas como eran Juan Luis de la Cerda o Baltasar de Céspedes. Sin embargo no eran muchos. Y tampoco era multitudinario el público. La prueba es que el Discurso no se llegó a publicar.

Volviendo a nuestro texto, la edición y anotación de la editora permite hacer una lectura más precisa y cómoda del contenido del Discurso y no quedar encallado en la multitud de referencias que da Céspedes. La anotación y las identificaciones bibliográficas siempre pertinentes permiten tener una nueva comprensión y valoración de la obra, colocar lo que dice Céspedes en el marco cultural de la época y no limitarse a una lectura plana, entendiendo las cosas a medias. Por ello hay que agradecer a Mercedes Comellas el buen trabajo realizado. Me hubiera gustado contar con un índice de autores anteriores a 1800 y un índice analítico de conceptos, que facilitaría el 
manejo y búsquedas en un estudio tan amplio que merecería más fácil acceso aunque sé que no es habitual en la colección ${ }^{11}$.

\section{NOTAS}

1. Un aficionado también a escribir consejos y planes de estudio para sus alumnos, por ejemplo en los ramistas y aristotélicos "Avisos per a estudiar les Arts en particular" que dejó manuscritos, cf. E. Duran-J. Solervicens (eds.), Renaixement a la carta, Bcn., Eumo, 1996, 90-92.

2. Se trata de dos estanzas ( $3^{\circ}$ y $4^{a}$ ) y las recibió Mey en 1577, «Rezién llegado yo a su servicio y haciéndole oferta de mi primer libro del Metamorfoseos» según indica en el prólogo. Sobre los versos romances de Agustín cf. A. Egido, «Numismática y literatura, de los diálogos de Agustín al museo de Lastanosa», Estudios sobre el Siglo de Oro. Homenaje a Francisco Ynduráin, Madrid, Editora Nacional, 1984, 211-227. En los textos castellanos que cito añado acentuación.

3. Del Metamorfoseos de Ouidio en otaua rima, traduzido por Felipe Mey, siete libros: con otras cosas del mismo, Tarragona: F. Mey, 1586. Las rimas petrarquistas de Mey se editan como segunda parte (otras cosas) que se cierran con la «Fuente de Alcover» (25-47) en la que aparece al final Ana [Llagostera], el objeto de sus rimas, que contesta a sus requiebros p. 45: Ni remediarte, a mi deber faltando, / Ni poder disponer de mí, me es dado: / Su tiempo llegara, Dios sabe el quando. Se casarán hacia 1580 y tendrán su primer hijo en agosto de 1581, cf. J. F. Alcina, «Nuevos datos sobre el impresor y helenista Felipe Mey», Revista de Estudios Latinos 5 (2005), 245-255 [247]. En este poema doméstico, Mey pretende cantar a personajes reales, históricos, todos vivos entre 1577 y 1579 (con noticias siempre exactas y podemos pensar que también en su relación con Ana nos cuenta una realidad que todos conocen). Y por tanto no creo que se escribiese fuera del período 1577-1579 o aunque se escribiese después, el autor pretendió mostrarnos una reconstrucción de ese momento.

4. «Luís Icarte» señor de Torredembarra, Batlle general de Catalunya en 1568 (Gran Enciclopèdia Catalana, s.v. «Almenar») vivía por lo menos en 1578 (cf. M. Palau, «Lluís Pons d'Icart i la Vila de Torredembarra» en Recull de Treballs. Centre d'Estudis Sinibald de Mas, 3 [1986], 30, en red) y murió el 4 de abril de 1579 (R. Conde, «L'Arxiu del Reial Patrimoni, fons de l'Arxiu de la Corona d'Aragó», Lligall 18 (2001), 23, consultable en red; Mey añade a sus dos hijos, Luis (eclesiástico) y Juan (militar) que llegaría a ser también Batlle general del Principado.

5. Y de los vivos que cita (A. de Covarrubias y J. de Grial, ambos relacionados con la Universidad de Salamanca, aunque este último no aparece en algunos mss. porque falleció en 1599, cf. 186*), sólo Grial publicó un poema. Es probable que Céspedes conociera una tradición manuscrita que nosotros documentamos sólo parcialmente (en el caso de Covarrubias). Curiosamente ambos eran también del círculo de contactos de Agustín: A. de Covarrubias era amigo de Agustín y compartían método, inscripciones y copistas de griego (J.F. Alcina, «Las marcas de agua del manuscrito Santes Creus 113...», Calamus Renascens 16, 2015, 7-26; A. Domingo Malvadi, «El viaje de los libros...» en I. Pérez Martín-M. Becedas, coords., Diego de Covarrubias y Leyva. El humanista y sus libros, Univ. De Salamanca, 2013, 117-118) y Grial era colaborador de Agustín en la edición de Isidoro. Sobre la poesía de Agustín quiero remitir a la parte que escribió Joan Salvadó sobre este tema (descubriendo además un poema nuevo) en la voz 'Agustín Albanell, A.' de J. F. AlcinaJ.Carbonell-J.Salvadó en J. F. Domínguez (ed.), Diccionario biográfico y bibliográfico del humanismo español (siglos XV-XVII), Madrid, Eds. Clásicas, 2012, 23-37 [32-33]. 
6. Entre los artículos sobre tema numismático de J.Carbonell, creo que es especialmente clarificador sobre las innovaciones de Agustín «El estudio de la iconografía numismática en el siglo XVI. Antonio Agustín malgré lui», en M. Campo (ed.), Les imatges monetàries: llenguatge $i$ significat, Barcelona, Museu Nacional d'Art de Catalunya-Gabinet Numismàtic de Catalunya, 2003, 119-135 (además de los que cita Comellas).

7. A. Agustín, Opera Omnia, Lucae: 1772, VII, 247, citada por J. Closa, «Las "In Aldi Manutii P.F. Orthographiam Annotationes" de don A. Agustín», Los humanistas españoles y el humanismo europeo (IV Simposio de Filología Clásica), Univ. de Murcia, 1990, 133-137[133]; Agustín dejó manuscrita una censura (Opera, VIII, 403-404) a la que Closa dedica unas interesantes páginas. Agustín atribuye la obra al padre, Paolo Manuzio (posiblemente con razón), al que tenía especial inquina (ignoro el motivo exactamente) que compartía con el grupo en torno a Pantagato y después con Orsini. Agustín cita con críticas irónicas la Ortographia en los Diálogos de medallas, ed. Jano, 1987, por ej. 461, pero nunca es tan tajante como en la carta citada; también se menciona en la bibliografía epigráfica que incluye al final, 467 (sin crítica alguna).

8. También lo cita Agustín a propósito de la inscripción barcelonesa CIL II 4514 (XLVIII, 711) de L. Caecilius Pap. Optatus (347). Pregunta B. (Rodrigo Zapata) si es falsa y le contesta A.(Agustín) que no lo es, sino que está mal interpretada, y que Morales «no tiene tal intención, antes ha trabajado mucho por escribir verdad, y dize lo que siente con todo buen zelo y candor; y esta inscrición confiessa que la tiene errada.» (346) Simplemente, Agustín sin acrimonia piensa que Morales tiene malas copias y las interpreta mal, pero sin ser falsario como fray Juan Annio o Ciríaco de Ancona que han recibido ya palmetazos en ese diálogo.

9. Onofrio Panvinio et les antiquités romaines, École française de Rome, 1996.

10. Se podría añadir la tesis de A. Soler, La correspondència d'Ottavio Pantagato, (2000) tesis accesible online en la UAB, con una amplia biografía; sobre el corrector de la Vaticana Gabriel Faerno y el resto del cenáculo se puede remitir a la síntesis de J. Carbonell, «Ambientes humanísticos en Roma (1545-1555). El cenáculo de O. Pantagato, A. Agustín y J. Matal», en G. Puigvert \& C. de la Mota (eds.), La investigación en el área de las Humanidades, Madrid, Biblioteca Nueva, 2009, 47-70 [62-69]. La noticia de este cenáculo empieza en la propia Laudatio funebris de A. Schott a Agustín (Amberes: Plantino, ca.1586, en 17); en la lista de Schott se incluye sorprendentemente a «Paulo Manutio Aldi filio», y podría ser la fuente de Céspedes que también lo incluye.

11. Por cierto hay algunos gazapos. Entre los que he anotado: De ordine docendi et studenti = et studendi, 115*; cessaut = cessauit 152* n. 432; audactur = audacter [?], 157*; Beroaldi Chronicom = Beroaldi Chronicon, 58; Juan Antonio = Juan Francisco, 113; franciscano = agustino, 60.

\section{AUTORES}

\section{JUAN FRANCISCO ALCINA ROVIRA}

Universitat Rovira i Virgili 